Supplement of Saf. Nucl. Waste Disposal, 1, 225-226, 2021

https://doi.org/10.5194/sand-1-225-2021-supplement

(C) Author(s) 2021. CC BY 4.0 License.

Supplement of

\title{
Participation of the foreign public in the site selection procedure: prerequisites and the question of informal participation
}

Silvia Schütte and Johannes Franke

Correspondence to: Silvia Schütte (s.schuette@oeko.de)

The copyright of individual parts of the supplement might differ from the article licence. 


\section{PARTICIPATION OF THE FOREIGN PUBLIC IN THE SITE SELECTION PROCEDURE}




\section{Public participation in the site selection procedure and its application to the foreign public}

- $\quad$ Rules on public participation are a cornerstone of the procedure established by the StandAG

- Comprehensively regulated in Chapter 2 of the statute (§§ 5-11 StandAG), inter alia:

" Formal participation process at every stage of the procedure (including EIA-participation): $§ 7$ StandAG, UVPG

॥ „Regional Conferences“ for possible siting regions: § 10 StandAG

» Informal participation: § 5 (3) StandAG

- $\quad$ Provisions are tailored to domestic participation

» Transboundary relevance of nuclear waste disposal

» Legal requirement regarding participation of the foreign public? 


\section{Formal participation process pursuant to $§ 7$ StandAG and UVPG (EIA and SEA)}

- Joint implementation of the participation procedures pursuant to $\S 7$ StandAG and UVPG (EIA and SEA)

- $\quad$ Relationship of legal requirements pursuant to $\S 7$ StandAG and UVPG respectively » Both statutes provide rules regarding information, written submissions and consultations of the public

" "Most-favoured-participation-principle": law with more extensive requirements prevails

- $\quad$ Application to foreign participation

" UVPG (EIA and SEA) provides specific rules for participation of the foreign public (e.g. translation, interpretation), but limited to countries where "significant environmental impact" can occur

» $\S 7$ StandAG applies to the general international public, but does not establish specific rules for the foreign public

»Conclusion:

" Everyone can participate

» Specific rules for participation of the foreign public pursuant to UVPG are limited to certain countries (e.g. translation) 


\section{Participation in the „Regional Conferences“ pursuant to $\S 10$ StandAG}

- Participation format for people living in or close to possible siting regions

- If siting region borders on another state, the interests of the foreign public concerned must be "considered equally" according to $\S 10$ ( 2 ) StandAG - but how?

- $\quad$ Defining the relevant foreign region

" The equivalence could be taken into account by selecting a geographic section that corresponds in its maximum extent to the largest German territorial authority bordering the siting region

- General Assembly

" The foreign citizens are to participate in the General Assembly - on the same level as the citizens of the domestic territorial authorities (next to the siting region)

- $\quad$ Representative body

" In lack of a concrete regulation the equal consideration should also be reflected here. The rules must at least allow for the eligibility of foreign citizens 


\section{Informal participation}

- The principles of participation in $\S 5$ StandAG show no difference between domestic and foreign public to be involved

- Informal participation is foreseen in $\S 5$ (3) StandAG (so too: "further development" of participation)

- In case - siting region borders on another state - there is an obligation to involve the foreign public, this could also apply to the (regional) informal participation

- "spillover effect" on the participation of the foreign public

" Otherwise, an informational and participatory "gap" could arise 
The research results presented are part of the BASE-commissioned research project "Challenges and success factors in cross-border public participation in the site selection procedure (HErüber)"

\section{Thank you!}

